Bibliotecas. Vol 39, № 1, enero - junio, 2021. EISSN: 1659-3286

URL: http://www.revistas.una.ac.cr/index.php/bibliotecas/index

DOI: http://dx.doi.org/10.15359/rb.39-1.4

Licencia: Creative Commons (BY-NC-SA) 4.0 Internacional

\title{
Uso de realidad aumentada en el diseño de recursos para la animación lectora*
}

\author{
Use of Augmented Reality in the Design of Resources for Reading Animation
}

Jairo Guadamuz-Villalobos

Universidad de Costa Rica, Costa Rica

https://orcid.org/0000-0002-0284-3656

Recibido: 12 de agosto $2020 \quad$ Aceptado: 05 de diciembre de 2020

Publicado: 21 de mayo de 2021

\section{Resumen}

En el presente artículo se hace una descripción de los resultados obtenidos en el Trabajo Final de Investigación Aplicada Creación de un libro álbum con realidad aumentada de la obra "La guardiana de la naturaleza y sus amigos salvan el río" como apoyo al proyecto Verde que te leo verde de la Fundación Leer / IBBY Costa Rica para obtener el grado de máster en bibliotecología y estudios de la información. Con el fin de motivar a estudiantes de 10, 11 y 12 años de edad a leer la obra y participar en los talleres de Fundación Leer / IBBY Costa Rica, se creó un libro álbum con realidad aumentada de la obra La Guardiana de la Naturaleza y sus amigos salvan el río, escrita por Jessica Sheffield e ilustrada por Shannon McWhriter. Para llevarlo a cabo se diseñaron diferentes recursos para ser agregados al libro mediante tecnología de realidad aumentada entre los que se encuentran un sitio web, vídeos, animaciones, figuras en 3D, imágenes y archivos de audio, así como una fotografía esférica 360. Al finalizar la creación del documento, este se utilizó en un taller sobre salud ambiental organizado por la Fundación Leer / IBBY Costa Rica, como parte de su proyecto Leo que te leo verde. El uso del libro en este taller fue evaluado por la facilitadora de la Fundación y por los estudiantes participantes. Los resultados de todo el proceso permitieron concluir que es posible crear, desde la biblioteca, recursos bibliográficos originales, y que el uso de realidad aumentada trae consigo resultados favorables en cuanto a animación lectora se refiere, así mismo, los estudiantes involucrados en esta investigación manifestaron considerar que el uso de esta tecnología les permitió tener un mayor interés en la lectura.

\section{Palabras clave}

Animación lectora, Realidad Aumentada, Bibliotecas, Libro Álbum, Tecnologías de la Información y Comunicación

\section{Abstract}

This article describes the results obtained in the Final Applied Research Project Creación de un libro álbum con realidad aumentada de la obra La guardiana de la naturaleza y sus amigos 
salvan el río como apoyo al proyecto Verde que te leo verde de la Fundación Leer / IBBY Costa Rica to obtain a master's degree in library science and information studies. In order to motivate 10, 11 and 12-year-old students to read the work and participate in the Fundación Leer / IBBY Costa Rica workshops, an album book with augmented reality of the work La Guardiana de la Naturaleza y sus amigos salvan el río, written by Jessica Sheffield and illustrated by Shannon McWhriter. To carry it out, different resources were designed to be added to the book using augmented reality technology. These include a website, videos, animations, 3D figures, images and audio files, as well as a 360 spherical photograph. At the end of the creation of the document, it was used in a workshop on environmental health organized by the Fundación Leer / IBBY Costa Rica, as part of its project Leo que te leo verde. The use of the book in this workshop was evaluated by the Foundation facilitator and by the students who participated in it. The results of the entire process allow us to conclude that it is possible to create original bibliographic resources from the library, and that the use of augmented reality brings with it favorable results in terms of reading animation, likewise, the students involved in this research stated that they consider that the use of this technology allowed them to have a greater interest in reading.

\section{Keywords}

Reading animation, Augmented Reality, Libraries, Album Book, Information and Communication Technologies

\section{Introducción}

La Bibliotecología es una ciencia dinámica que ha experimentado cambios, reconfiguraciones y ampliaciones en virtud de adaptarse a los avances tecnológicos, a los cambios políticos, culturales y sociales y a las transformaciones en los hábitos de consumo de información. Así también, las diferentes actividades que la componen han ido cambiando su ejecución y la animación a la lectura no es la excepción. Debe entenderse por animación lectora la búsqueda de un encuentro entre el texto y el lector, de forma tal que se permita una mediación entre dichos elementos a través de actividades que lo motiven.

En la sociedad de la información y el conocimiento, este intento de acercar el usuario a la lectura debe considerarse una de las características de la información consumida hoy: lo digital. Jiménez (2012) afirma que "la lectura en la era digital en la que vivimos requiere, no sólo el dominio de lo escrito, sino y especialmente de lo visual" (p. 62). Es decir, se trata de buscar transformaciones en las prácticas de animación lectora que utilicen elementos como la imagen para enriquecer la estrategia de motivación. 
Las Tecnologías de la Información y la Comunicación (TIC), por su parte, ofrecen una gama de posibilidades en la producción, edición y difusión de información en todas sus formas, escenario que puede incluir la creación de imágenes. Por lo tanto, se plantea una combinación entre las TIC y la animación lectora que permitan la generación de productos para incentivar el acercamiento al acto de leer.

El uso de las TIC en la animación lectora también posibilita la creación de productos dinámicos que favorecen la interacción entre el lector con la obra, de forma que se crea un mayor vínculo entre ambos. Surge entonces la figura de una obra que además de su texto y sus ilustraciones, incluya desarrollos tecnológicos para enriquecer la experiencia del lector y buscar nuevos escenarios en la animación lectora.

Tomando en cuenta estos antecedentes se contactó a la Fundación Leer / IBBY Costa Rica, quien tiene proyectos de animación lectora en bibliotecas de la provincia de Cartago. Sus proyectos poseen poblaciones cautivas y se tramitaron los permisos correspondientes para trabajar con estas comunidades. Se eligió una obra para la animación lectora vinculada con temas de vanguardia como el medio ambiente y el correcto cuidado de la naturaleza. Estas condiciones convierten a la Fundación en la institución oportuna para vincular el desarrollo de la presente investigación.

Entre los proyectos de la Fundación destaca "Verde que te leo verde", el cual trabaja con la obra ilustrada La guardiana de la naturaleza y sus amigos salvan el río, escrito por Jessica Sheffield Zamora, e ilustrado por Shannon McWhirter. Dicho libro narra la historia de Lucía, una niña que descubre cómo la basura que llega al río está causando un daño significativo a la naturaleza que ella tanto ama.

Si bien, la obra ya se encuentra ilustrada, dichas ilustraciones son óptimas para despertar el interés de un público meta muy joven, tales como estudiantes de primero, segundo y tercer grado. Diagramar nuevamente el cuento con fotografías y realidad aumentada podría despertar el interés en la obra de estudiantes de edades más avanzadas, es decir, de 9 a 11 años de edad, permitiendo no solo la interacción de los jóvenes lectores con el texto y las imágenes, sino también con 
elementos tecnológicos insertos en la misma obra a través del uso de la realidad aumentada. Por lo tanto, se plantea la siguiente pregunta de investigación: ¿Es posible utilizar la tecnología de realidad aumentada para enriquecer obras ilustradas, de forma tal que le ofrezca a los lectores nuevas experiencias en la lectura? Para contestar dicha pregunta, la presente investigación tiene como objetivo general: Crear un libro álbum con realidad aumentada de la obra La guardiana de la naturaleza y sus amigos salvan el río como apoyo al proyecto "Verde que te leo verde" de la Fundación Leer / IBBY Costa Rica.

Asimismo, los objetivos específicos considerados para la presente publicación son: Generar recursos multimedia que apoyen el texto de la obra La guardiana de la naturaleza y sus amigos salvan el río mediante el uso de realidad aumentada; Coadyuvar con el desarrollo de un taller del proyecto "Verde que te leo verde" de la Fundación Leer/ IBBY Costa Rica a través del libro álbum de la obra La guardiana de la naturaleza y sus amigos salvan el río; Evaluar el uso del libro álbum de la obra La guardiana de la naturaleza y sus amigos salvan el río aplicado en el taller del proyecto "Verde que te leo verde". El cumplimiento de estos objetivos permitirá conocer las posibilidades que ofrece esta tecnología para la animación lectora y considerarla para su aplicación en programas de animación lectora de las bibliotecas.

\section{Referente teórico}

\section{a. Generalidades sobre la animación lectora}

La lectura se considera una actividad que dota de sentido a nuestra realidad y facilita la transmisión cultural y del conocimiento. La necesidad de transmitir información de generación en generación se vio altamente beneficiada con la escritura y, por tanto, con la lectura como tal. La lectura no solamente se trata de interpretar intelectualmente un texto, como se haría con un documento académico, pues existen también los casos en los que el contenido del documento provoca sentimientos y emociones más allá del ejercicio intelectual (Castillo, 2011). Existen obras en las cuales sus autores lo que buscan es provocar un sentimiento, por lo que no se puede adscribir únicamente al intelecto el proceso lector; de hecho, se trata de una reacción más compleja donde pueden manifestarse emociones, reflexiones y pensamientos críticos. La 
lectura se trata de una reacción compleja "leer es reaccionar adecuadamente ante un texto determinado, dentro de un cierto contexto" (Piedrasanta, citado por Castillo, 2011, p.13).

Al respecto, para lograr el desarrollo de un hábito de lectura, es necesario que el futuro lector sea motivado a acercarse a esta actividad, buscando que ese acercamiento se vea como una invitación atractiva y no como un acto impositivo. Al respecto, Pernas Lázaro afirma que "Se busca que el niño se apropie de la lectura de forma natural así que es fundamental que existan espacios y momentos de lectura que no estén asociados al desarrollo de competencias" (2009, p. 268).

Por lo tanto, es importante entender la lectura como una actividad placentera, que ofrece una integración de disfrute, aprendizaje y crecimiento personal. La lectura es una oportunidad para generar procesos de aprendizaje en la persona lectora; pero al mismo tiempo se trata de una actividad divertida, un pasatiempo, una de las formas más oportunas de disfrute y aprendizaje: "La lectura nos enseña el camino hacia el conocimiento, nos hace adentrarnos en una experiencia de aprendizaje continuo, de renovación y, sobre todo, de sorpresa y de emoción" (Chaves, 2019, p. 4).

El acercamiento a la lectura se gestiona desde el proceso mismo de animación lectora, que puede definirse como el medio por el que se consigue que personas poco o nada familiarizadas con el hábito puedan convertirse en nuevos lectores y, a la vez, acompaña a lectores ya formados a continuar con el desarrollo de su hábito. Se trata de un proceso planificado, con un diseño previo y dispuesto a ser evaluado una vez terminado el proceso (Lluch y Sánchez, 2017). Es decir, la animación lectora responde a una estructura ordenada, pensada con detenimiento, en la que convergen actividades con objetivos específicos en busca de resultados concretos, incluso pueden ser parte de un proyecto aún más grande que le exija una estructura ordenada y claramente planificada.

La animación lectora, una vez implementada, permite que los lectores puedan independizarse poco a poco, de modo que pasan de las lecturas acompañadas a elegir sus propios libros, identificar sus gustos literarios y generar su propio criterio con respecto a lo que lee. La lectura 
mejora la ortografía, desarrolla el sentido crítico y amplía el vocabulario de aquellos que la practican como un hábito; por lo tanto, las bibliotecas han invertido su tiempo y recursos en generar espacios para promover el hábito de la lectura.

La animación lectora es una actividad que las bibliotecas pueden asumir con un papel protagónico. Según Ramírez Leyva (2009)

La lectura es una de las problemáticas que desde luego atañen a los bibliotecólogos en su actividad científica, pedagógica y profesional. Por tanto, no conviene desestimar las ideologías y teorías anidadas en ellos, pues actúan en nosotros, aunque en ocasiones poco o nada sepamos al respecto (p. 164).

La planificación detallada, el conocimiento sobre buenas prácticas en la animación lectora y los hallazgos científicos acerca de sus beneficios son parte de los conocimientos que debe dominar un profesional de la información. Por tanto, la biblioteca se considera un escenario óptimo para generar espacios de animación a la lectura. El profesional en bibliotecología puede tomar el papel de curador, al seleccionar oportunamente los textos que utilizará para la animación lectora; de facilitador, al encargarse de la parte logística de la actividad; puede ser promotor y encarnar el papel de guía en medio de talleres y clubes de lectura; y puede ser formador, teniendo un papel activo en los procesos de enseñanza y aprendizaje que la animación lectora hace posible. No obstante, también puede convertirse en productor, es decir, tener la capacidad de elaborar su propio material de apoyo para la animación a la lectura.

Chaves Salgado (2015) propone varias ideas para la elaboración de talleres de animación lectora; $y$ entre los materiales tomados en cuenta por la autora pueden identificarse desde fichas de colores, lapiceros, libros de cuentos, cuadernos, fotos y dibujos, hasta los mismos niños como agentes activos dentro de la dinámica planteada. Chaves Salgado también deja claro que toda actividad debe estar planteada hacia la importancia del libro en la vida de las personas "Su utilidad debe enfocarse en destacar el papel fundamental del libro y el modo en el cual este debe pasar a formar parte de la vida integral de las personas" (2015, p. 14). 
Otro de los recursos útiles en la animación lectora es el libro álbum, el cual es también un recurso que puede ser diseñado y producido por el personal de la biblioteca; además, tomando en cuenta lo expuesto por Chaves Salgado (2015) puede generarse una mayor reflexión sobre la importancia del libro en la vida de la población usuaria utilizándolo como material dinamizador de la actividad. Sin embargo, a diferencia de otros recursos, la construcción de un libro álbum debe cuidar aún más la estética, debido a la importancia que tiene la imagen en la obra por sí misma. Así lo afirma la Unidad de Curriculum y Evaluación del Ministerio de Educación de Chile (2007):

En el libro álbum la imagen es prioritaria, ella es la que da el tono, la atmósfera, el sentido. La ilustración es aprehendida a través de la emoción, la sensibilidad, a través de la asociación de formas, colores, ideas y referentes (mediante un trabajo de decodificación). (p. 69).

Este cuidado de la estética del recurso lleva a los editores a conformar equipos interdisciplinarios entre escritores, diseñadores gráficos e ilustradores (Unidad de Curriculum y Evaluación del Ministerio de Educación de Chile, 2007). De quererse replicar el proceso en una unidad de información de manera artesanal es importante saber que la ilustración puede construirse con recursos accesibles al público general. Una fotografía, tomada incluso con la cámara de un dispositivo móvil, si cuida su estética y se planifica como parte de un proyecto de diseño que involucre todos los elementos del libro, puede aportar el peso de la imagen que las editoriales buscan a través de la ilustración.

\section{b. Realidad aumentada}

La realidad aumentada (RA) puede verse como la combinación de escenas reales con información digital, mostrando ambas realidades de manera integral a través de la pantalla de un computador o un dispositivo móvil (Cabero, Vázquez y López, 2018). Esta integración es posible gracias a la inclusión de cámaras de video en diferentes tipos de dispositivos.

La experiencia comienza con la habilitación de la cámara y la captura en su pantalla de lo que el sensor está percibiendo de la realidad. Una vez que se muestra la escena en el dispositivo este, mediante aplicaciones especializadas, logra combinar imágenes, vídeos y contenido 
virtual previamente diseñado, con la escena capturada por la cámara. Este proceso se realiza en tiempo real, por lo que cualquier persona que aparezca en la cámara del aparato parecerá que interactúa con el objeto virtual de forma inmediata.

La tecnología RA permite la imitación de efectos especiales que antes solo eran posible mediante la edición de montajes fotográficos o el uso de equipo especializado de video (como cromas o fondos de separación de personajes). Esto permite la creación de experiencias enriquecidas con objetos virtuales de forma rápida y en tiempo real. En palabras de Flores, Domínguez y Rodríguez: "Esta nueva tecnología complementa la percepción e interacción con el mundo real y permite al usuario estar en un entorno real aumentado con información adicional generada por el computador" (2010, p. 2).

Existen dos tipos de realidad aumentada: la realidad aumentada geolocalizada, que consiste en la activación de contenido adicional mediante la ubicación geográfica de un dispositivo móvil, esto gracias a la brújula, el GPS o el acelerómetro que posea el aparato en su hardware. También existe la realidad aumentada basada en marcadores, que consiste en la lectura de una imagen denominada marcador, a la cual se le asocian contenidos adicionales. Estas imágenes pueden ser códigos QR, fotografías o imágenes prediseñadas, o bien figuras geométricas (Blázquez, 2017).

Adicionalmente, la realidad aumentada puede clasificarse en cuatro niveles diferentes, según Prendes (2015) existe el nivel 0, el cual es posible gracias a los códigos QR y los códigos de barra; se trata de un hiperenlace en el mundo físico para acceder a contenido digital, tal es el caso de la dirección URL incluida en un código QR, la cual, al leerla con la cámara de un dispositivo puede cargar el contenido de un sitio web. También existe el nivel 1, el cual se logra mediante el reconocimiento de una imagen 2D o un objeto 3D llamados marcadores. Tras dicho reconocimiento se desprende contenido adicional sobre el marcador seleccionado permitiendo no solo la exposición del contenido relacionado sino también el seguimiento de este en caso de mover el marcador de lugar. 
El nivel 2 es una realidad aumentada más compleja, se basa en el reconocimiento geoespacial del dispositivo móvil, por lo que no requiere marcadores para mostrar contenido virtual mezclado con la realidad haciendo uso de las coordenadas de ubicación, la brújula, el giroscopio y otros elementos del hardware del dispositivo utilizado. Finalmente, existe el nivel 3, el cual aún se encuentra en desarrollo, y se trata de poder visualizar todo el contenido virtual en dispositivos mucho más ligeros, como lo ha logrado Google con sus gafas inteligentes. Este último nivel supone un siguiente paso de integración mediante lentes de contacto o, porque no, "interfaces directos al nervio óptico y el cerebro" (Prendes, 2015, p. 190). Aunque se trate aún de una propuesta ya se aborda el término visión aumentada que supone una combinación total del mundo físico con el virtual, trayendo consigo una experiencia completamente diferente de la realidad.

La realidad aumentada no está ajena a las bibliotecas. Además de la posibilidad de crear obras con imágenes digitales que parecen emerger de sus páginas, las unidades de información pueden idear otros proyectos para sacar su máximo provecho en la prestación de sus servicios. Pueden mencionarse ideas como: el uso de RA a la hora de recorrer los estantes en busca de documentos; el uso de RA para la animación lectora (que está altamente vinculado con la construcción de obras con ilustraciones emergentes de sus páginas); o el uso de RA para la exposición de nuevos ejemplares o para la promoción de actividades y servicios. Al respecto Arroyo (2016) sugiere las siguientes ideas para integrar la realidad aumentada en las unidades de información: geolocalización de puntos de servicio, dinamización de exposiciones y otras actividades, publicaciones enriquecidas, espacios físicos de las bibliotecas y, finalmente, alfabetización informacional y ludificación. En síntesis, la realidad aumentada, como tecnología emergente, ofrece un alto potencial para integrarse en una cantidad significativa de escenarios dentro de las labores bibliotecológicas.

\section{Metodología}

\section{a. Elaboración de material para realidad aumentada}

Aumentaty Creator es un software de escritorio gratuito que permite la creación de contenido visible por realidad aumentada a través de marcadores que pueden ser asignados desde la 
misma aplicación. Sus creadores también generaron una aplicación para móviles llamada Scope, que permite visualizar las creaciones en realidad aumentada.

Entre los contenidos creados se incluyeron audios con sonido de la naturaleza, para potencializar la experiencia de lectura de la obra, animaciones breves sobre el relato, vídeos sobre algunos de los eventos de la obra, fotografías con escenas adicionales y modelos en 3D. Como parte de la inclusión del material de apoyo a la obra, en diferentes páginas se incluyeron marcadores para consultar vídeos educativos sobre cómo cuidar el medio ambiente.

Para la integración de los marcadores a la obra se utilizó el software Adobe InDesign, y una vez terminada la integración se imprimió y empastó el documento para ser utilizado en uno de los talleres de animación lectora de la Fundación Leer/IBBY Costa Rica. Para dichos efectos fue necesario que los estudiantes participantes tuviesen acceso a dispositivos móviles con la aplicación Scope previamente instalada. Para facilitar esta tarea se utilizaron los dispositivos personales de los participantes, pues las tabletas de la Escuela de Bibliotecología y Ciencias de la Información de la Universidad de Costa Rica no disponían de la versión de sistema operativo Android necesaria.

Tras la conclusión de esta etapa se obtuvo una versión impresa del libro álbum con realidad aumentada el cual, al ser consultado, no solo presentó la obra de Sheffield debidamente ilustrada con fotografías, sino que además permitió que el lector, mediante el uso de un dispositivo móvil, consumiera información adicional de forma dinámica y entretenida, reflexionara sobre el cuidado del ambiente y conociera más sobre las iniciativas del Movimiento Guardianes.

\section{b. Configuración de realidad aumentada con Aumentaty}

Todos los recursos de realidad aumentada deben estar relacionados con un marcador. Los marcadores son imágenes que después de la configuración necesaria, pueden ser leídas por un dispositivo móvil y sobre su superficie logran mostrar recursos adicionales, tales como vídeos, enlaces web, imágenes, figuras en 3D o texto. 
Para lograrlo fue necesario utilizar dos aplicaciones. La primera de ellas fue Creator, un software gratuito desarrollado por la Comunidad Aumentaty. La Comunidad Aumentaty es "Un espacio donde los usuarios pueden crear y compartir proyectos de RA creados por ellos, poder enviarlos a otros usuarios que podrán utilizarlos, editarlos y volver a compartirlos" (Aumentaty, 2019, párr. 2). Su software Creator es compatible con el sistema operativo Microsoft Windows y permite crear proyectos de realidad aumentada y compartirlos en la comunidad. Para crear el contenido de realidad aumentada de la obra fue necesario establecer una cuenta en la Comunidad, se descargó e instaló el software Creator y se generó un proyecto con el nombre "Guardianes de la Naturaleza".

Los proyectos de RA creados deben tener fichas y estas fichas son las que permiten asociar diferentes recursos a una imagen definida denominada marcador. Por lo tanto, se crearon 14 marcadores para relacionar los diferentes recursos desarrollados. En cada recurso fue necesario asignar una ubicación de este en relación con su marcador. (Ver Figura 01).

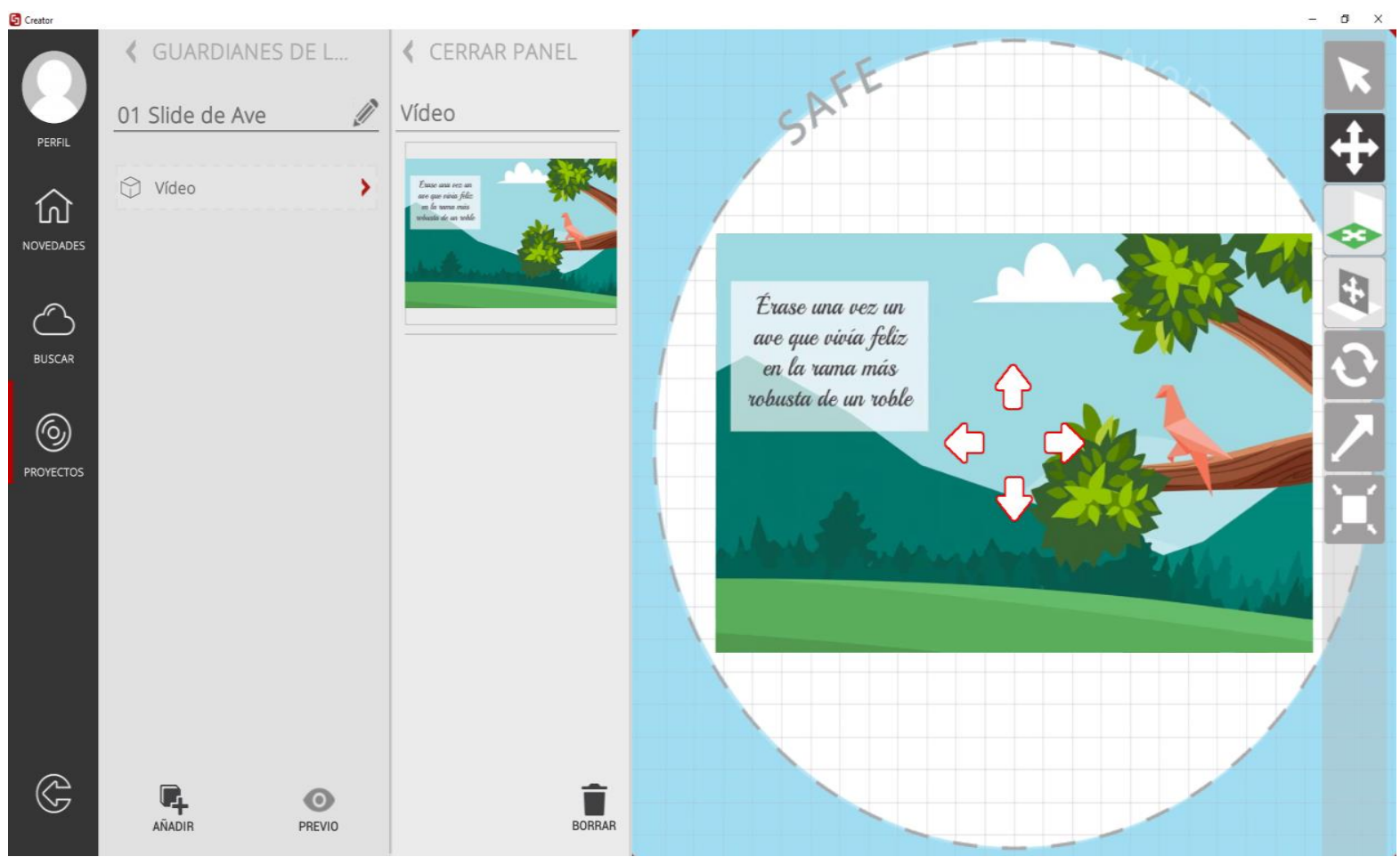

Figura 01. Ubicación de elemento en marcador de Aumentaty

Fuente: Elaboración propia del autor, 2020. 
Al finalizar la creación de todas las fichas se publicó el proyecto para que otras personas pudieran descargarlo a sus dispositivos y así poder consultar el contenido de realidad aumentada. Una vez publicado el proyecto se descargó a un dispositivo móvil a través de la aplicación Scope y así, al habilitarse la cámara, el dispositivo está en capacidad de leer todos los marcadores del proyecto y mostrar el contenido RA respectivo sobre cada uno de ellos. El Cuadro 1 muestra el contenido RA creado junto con el marcador asignado a cada uno de los recursos, así como una captura de pantalla de cómo se visualiza cada recurso desde el dispositivo móvil.

\section{Cuadro 1}

Lista de marcadores y contenido relacionado

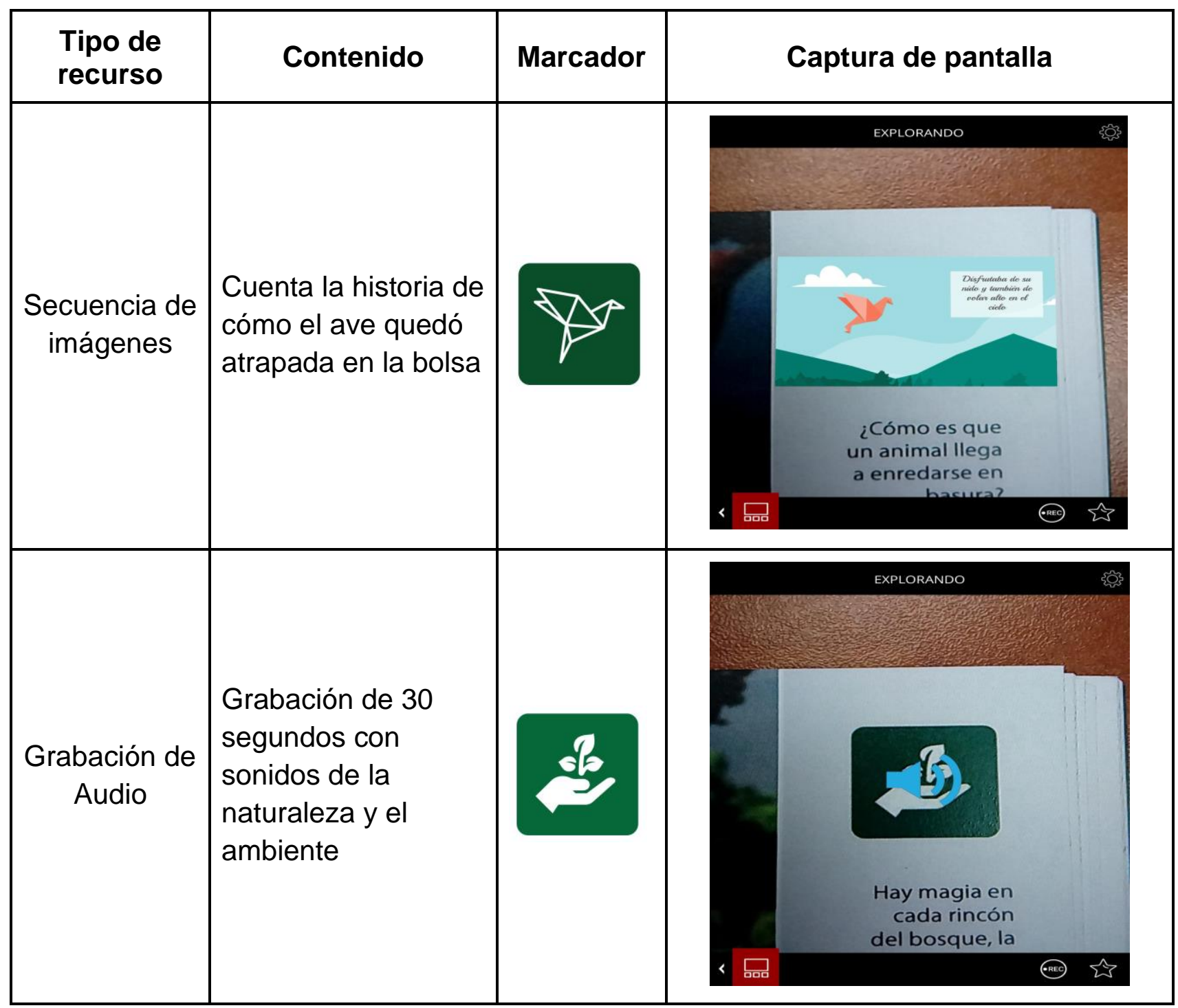


Bibliotecas. Vol. 39, № 1, enero - junio, 2021. EISSN: 1659-3286 URL: http://www.revistas.una.ac.cr/index.php/bibliotecas/index

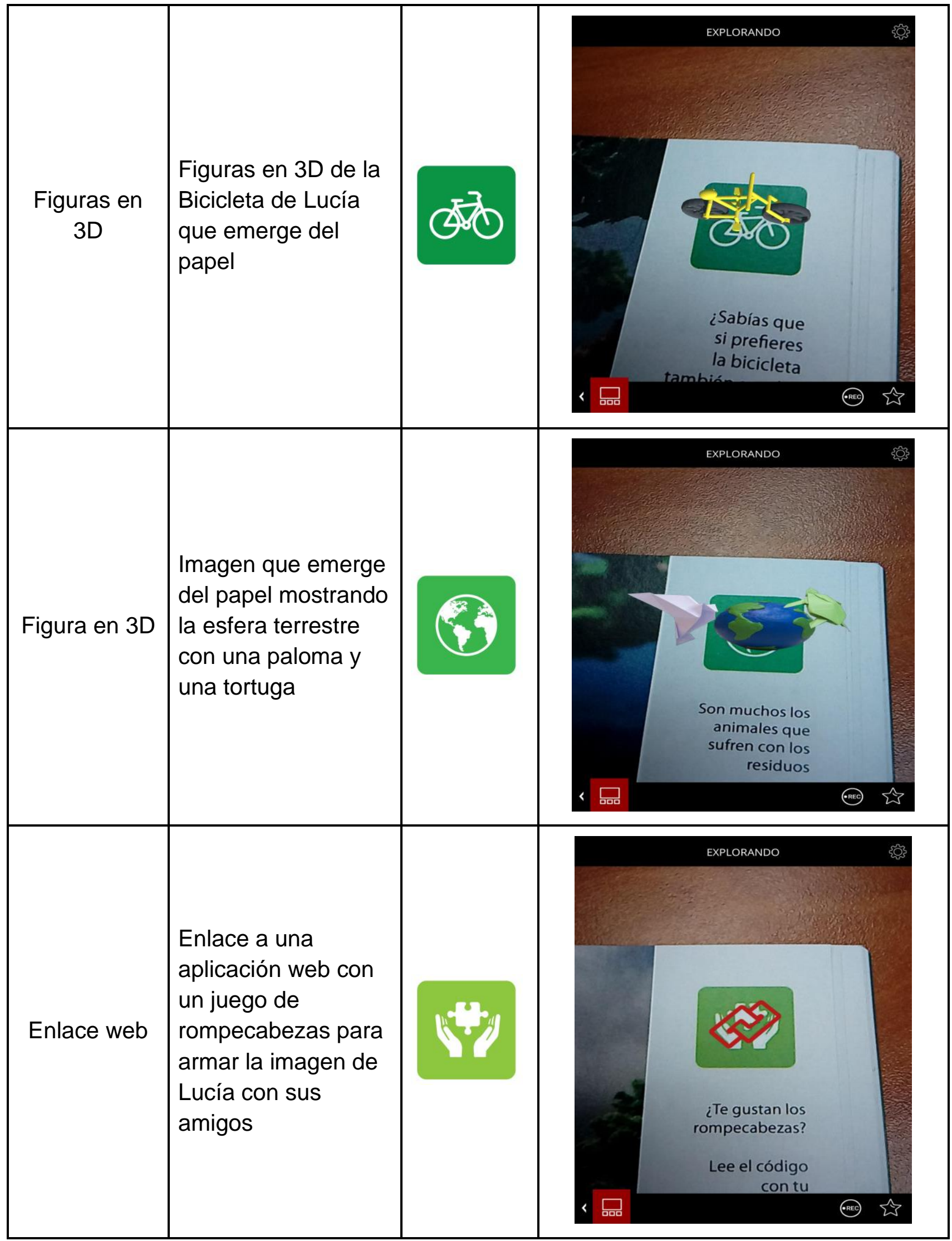


Bibliotecas. Vol. 39, № 1, enero - junio, 2021. EISSN: 1659-3286 URL: http://www.revistas.una.ac.cr/index.php/bibliotecas/index

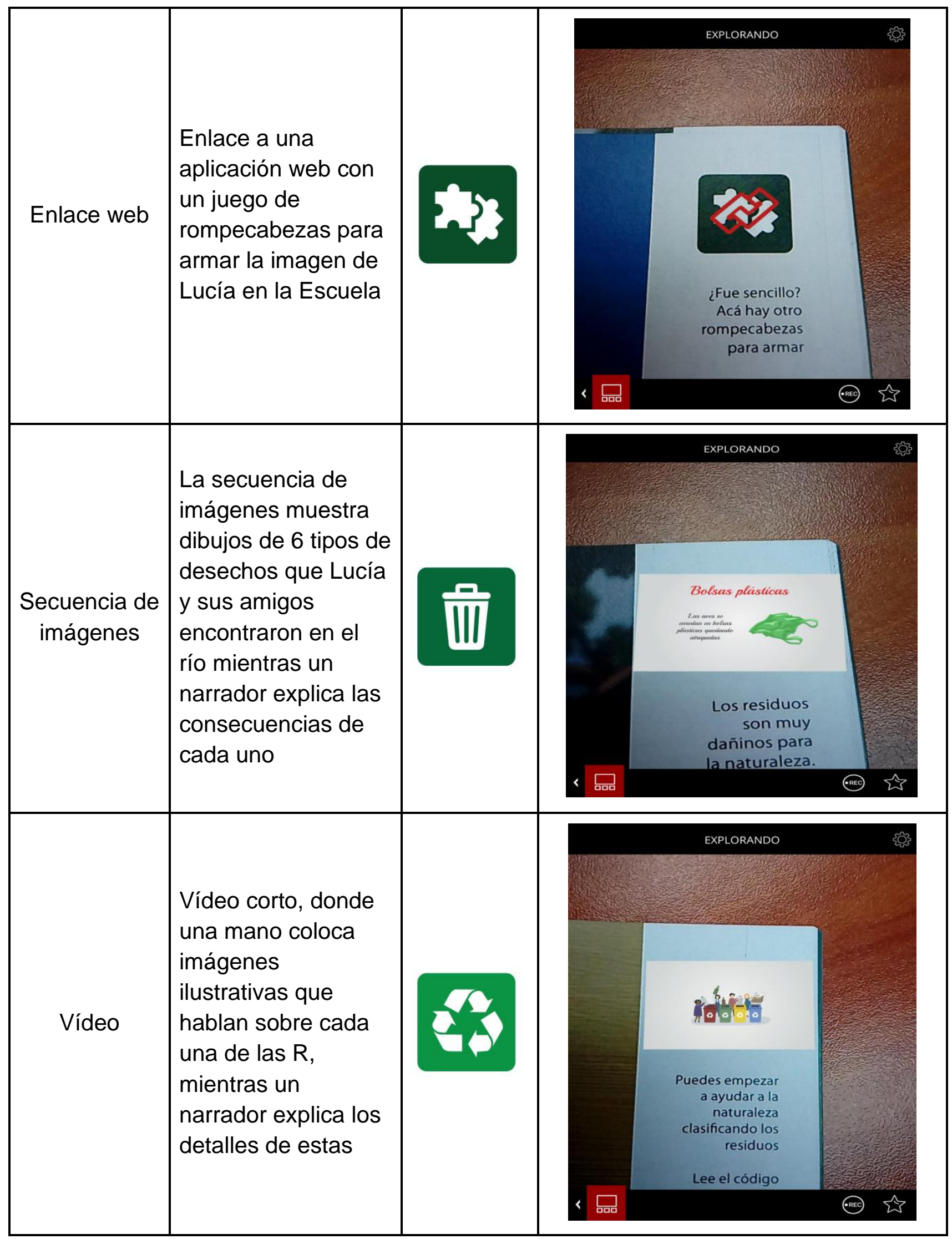


Bibliotecas. Vol. 39, № 1, enero - junio, 2021. EISSN: 1659-3286 URL: http://www.revistas.una.ac.cr/index.php/bibliotecas/index

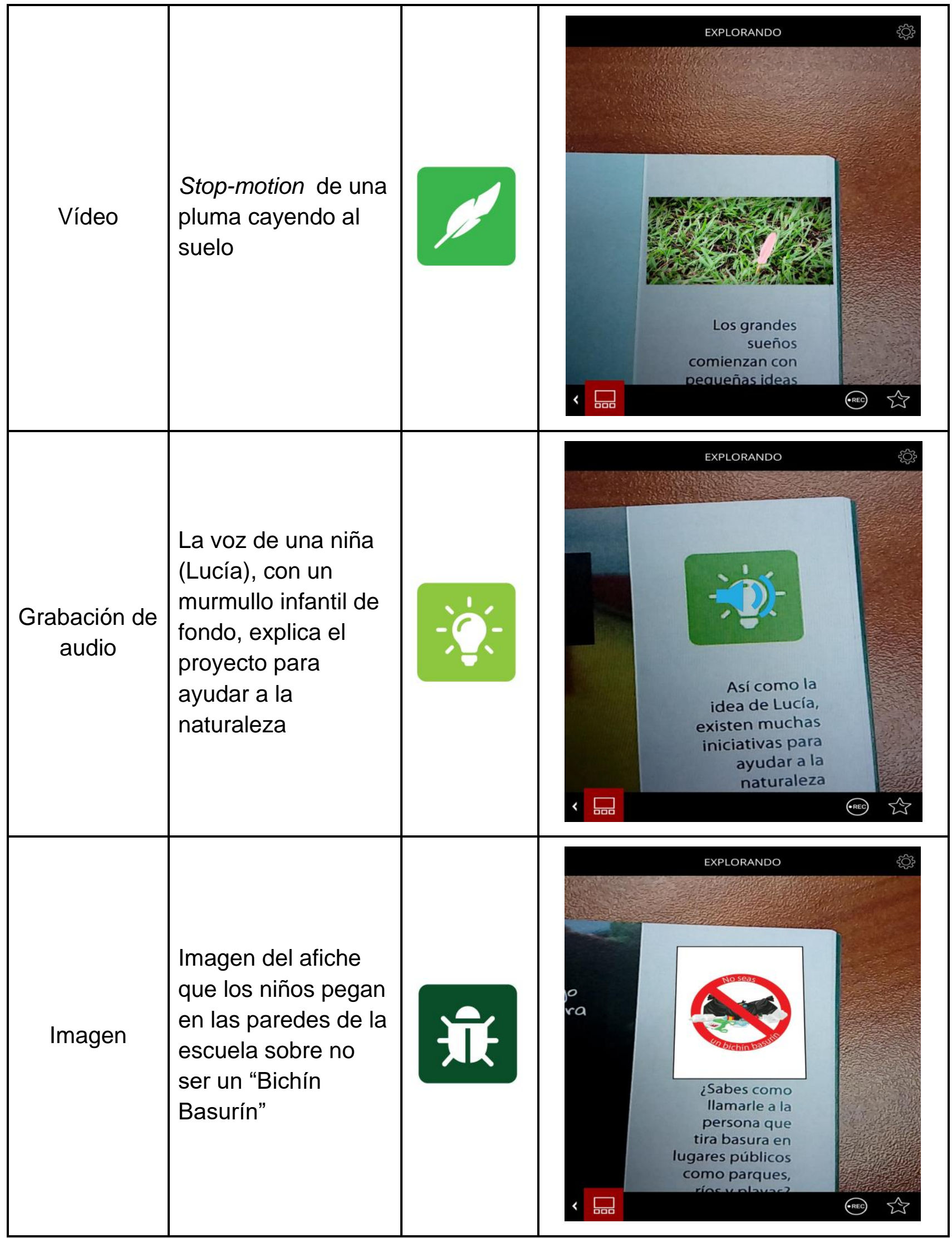


Bibliotecas. Vol. 39, № 1, enero - junio, 2021. EISSN: 1659-3286 URL: http://www.revistas.una.ac.cr/index.php/bibliotecas/index

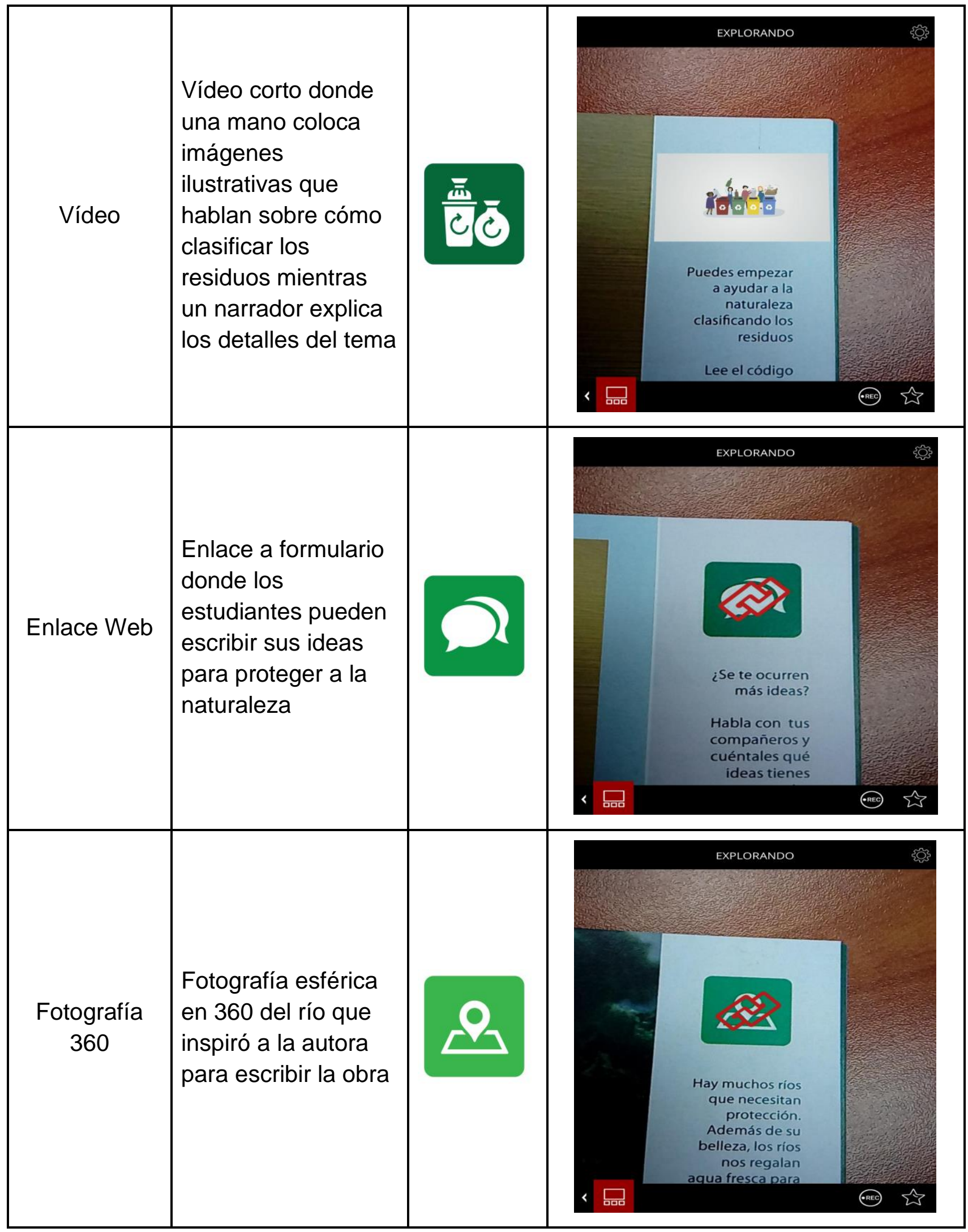

Fuente: Elaboración propia del autor, 2020. 
Como apoyo al proyecto desarrollado en la presente investigación, se creó material audiovisual que muestra las diferentes etapas de diseño, creación e implementación del libro álbum con realidad aumentada. Dicho material consiste en un vídeo corto de carácter ilustrativo que muestra únicamente las escenas más representativas de la producción del libro (disponible en: https://youtu.be/AmssyAnA338) y un vídeo más extenso que incluye comentarios del investigador sobre todo el proceso llevado a cabo en la presente investigación (disponible en https://youtu.be/qGOsfZIXFQc).

\section{Resultados}

El día 22 de julio de 2019, a partir de las 12:30 del mediodía, se realizó uno de los talleres del proyecto "Leo que te leo verde" proyecto en el cual la Fundación Leer / IBBY Costa Rica facilita material didáctico para abordar la promoción de lectura mediante la temática de la protección del medio ambiente. Para este taller en particular se utilizó el libro álbum elaborado en la presente investigación, del cual se imprimieron seis copias a color, debidamente guillotinadas y engrapadas al centro. Junto a las seis copias del libro se llevaron al lugar 18 copias del instrumento diseñado para la valoración del estudiantado (Anexo I).

El taller inició cargo de la facilitadora de la Fundación Leer / IBBY Costa Rica, quien realizó una breve explicación del libro, indicando al estudiantado que se trataba de un libro con material adicional que podrían consultar a través de dispositivos móviles. Seguidamente, se organizó la clase en seis tríos de estudiantes, dándole a cada uno de estos subgrupos una copia del libro, un dispositivo móvil y varios juegos de marcadores impresos en tamaño carta.

La lectura del libro fue dirigida por la facilitadora, quien indicaba en qué momento podían utilizar el dispositivo móvil disponible para leer cada marcador. De esta manera el grupo de estudiantes leyó el libro completo y reprodujo todos los contenidos de realidad aumentada del libro. Ante cada lectura se manifestaron expresiones de asombro entre los niños y las niñas participantes. Entre los contenidos con mejor acogida por parte del grupo lector destacan la Figura 3D de la bicicleta, la imagen del globo terráqueo y los animales en origami, el audio de la naturaleza y los rompecabezas (Ver Figura 02). 
Desde la técnica de observación el investigador también notó que la reproducción con marcadores pequeños es oportuna si se utilizan teléfonos móviles, mientras que los marcadores grandes se desprenden mejor si se trata de tabletas. La experiencia de lectura en grupos se pudo observar cómo atinada, ya que un miembro del grupo sostenía el libro mientras otro miembro realizaba la lectura del marcador (Ver Figura 03).
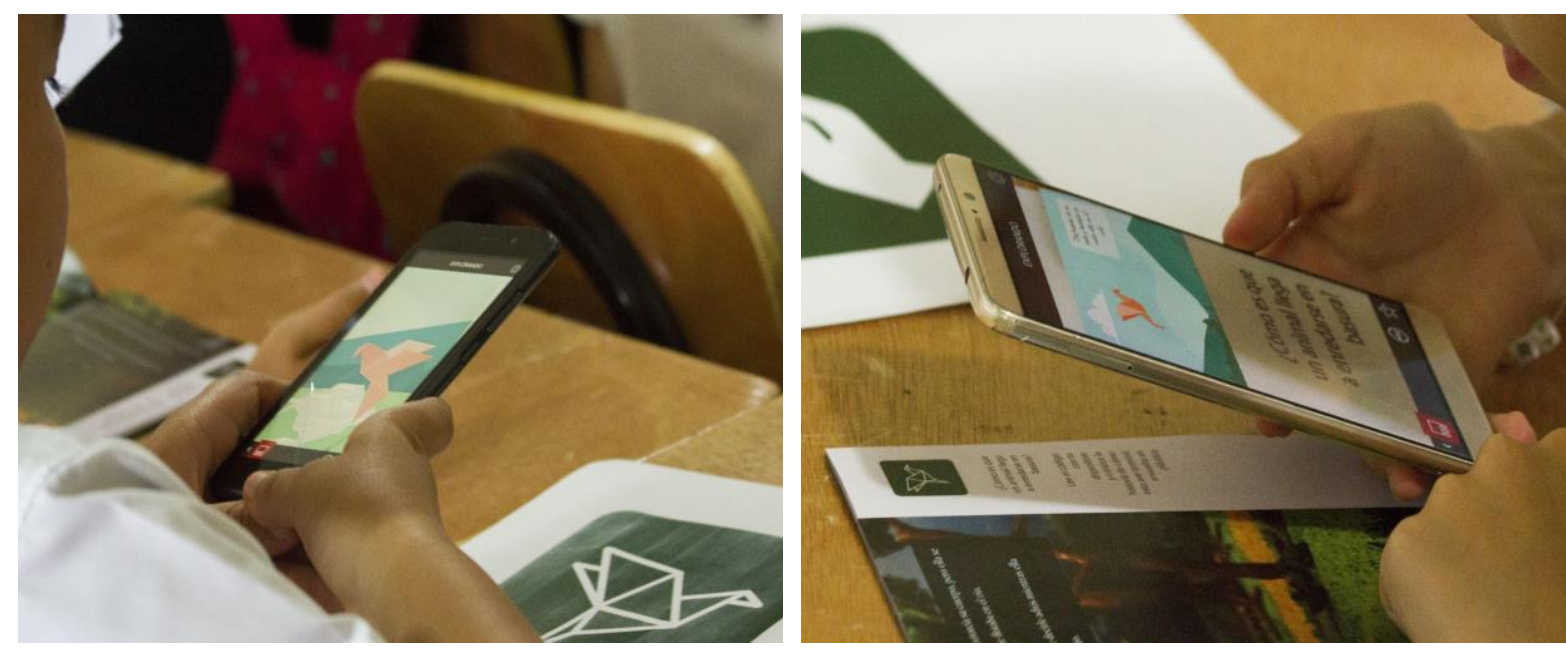

Figura 02. Estudiantes consultando los elementos de realidad aumentada

Fuente: Elaboración propia del autor, 2020.
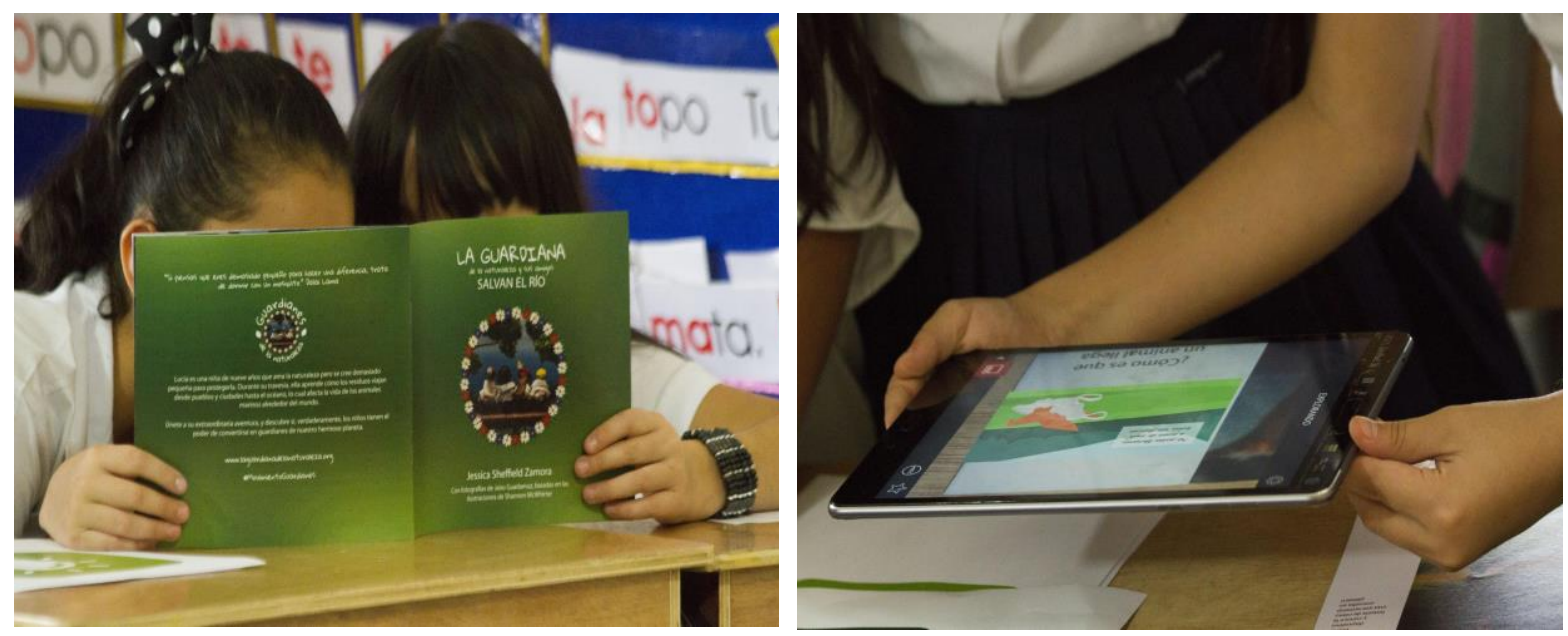

Figura 03. Estudiantes leyendo el libro álbum en equipo

Fuente: Elaboración propia del autor, 2020. 
Al avanzar con la lectura el grupo lector fue familiarizándose cada vez más con el uso de realidad aumentada, al punto de que los últimos marcadores fueron leídos con mayor rapidez. También se observó cómo el estudiantado socializaba la experiencia entre sí, mostrándose la pantalla del dispositivo mutuamente y realizando comentarios de asombro y de interés acerca de los marcadores y el contenido RA relacionado. Una vez concluida la lectura se suministró una copia del instrumento de valoración a cada una de las personas participantes.

El grupo de estudiantes que participó en la evaluación estuvo conformado por 10 mujeres y 8 hombres, distribuidos en 5 estudiantes con 9 años de edad, 10 estudiantes con 10 años y tan solo 3 con 11 años. La mayoría de las personas participantes, con un $88.8 \%$, consideró que el libro es fácil de utilizar marcando la opción completamente de acuerdo, mientras que un 11,2\% se mostró muy de acuerdo. $61.1 \%$ de los estudiantes estuvo completamente de acuerdo en que las instrucciones para instalar la aplicación Scope son útiles, mientras que el $27,7 \%$ y el $11,1 \%$ estuvo muy de acuerdo y de acuerdo, respectivamente. Posteriormente, $77,8 \%$ de los estudiantes estuvo muy de acuerdo en que los contenidos vistos con la tableta ayudaron a comprender la historia, mientras que un $11,1 \%$ estuvo muy de acuerdo y el mismo porcentaje de entrevistados se mostró de acuerdo.

Con respecto a la afirmación Tienes más interés en el medio ambiente y en el cuento gracias a los contenidos vistos en la tableta, $66,7 \%$ estuvo completamente de acuerdo, $27,7 \%$ muy de acuerdo y $5,6 \%$ de acuerdo. Además, en la pregunta La lectura es más divertida al encontrar contenido adicional usando la tableta, $66,7 \%$ aseguró estar completamente de acuerdo, mientras que $22,2 \%$ y $11,1 \%$ afirmó estar muy de acuerdo y de acuerdo, respectivamente. Finalmente, todos los estudiantes opinaron que la obra debería ser utilizada en otras escuelas, indicando la opción completamente de acuerdo con un $88.8 \%$, muy de acuerdo con un $5.6 \%$ y de acuerdo, también con un porcentaje de $5.6 \%$. Todos estos resultados se pueden visualizar más claramente en la Figura 04. 


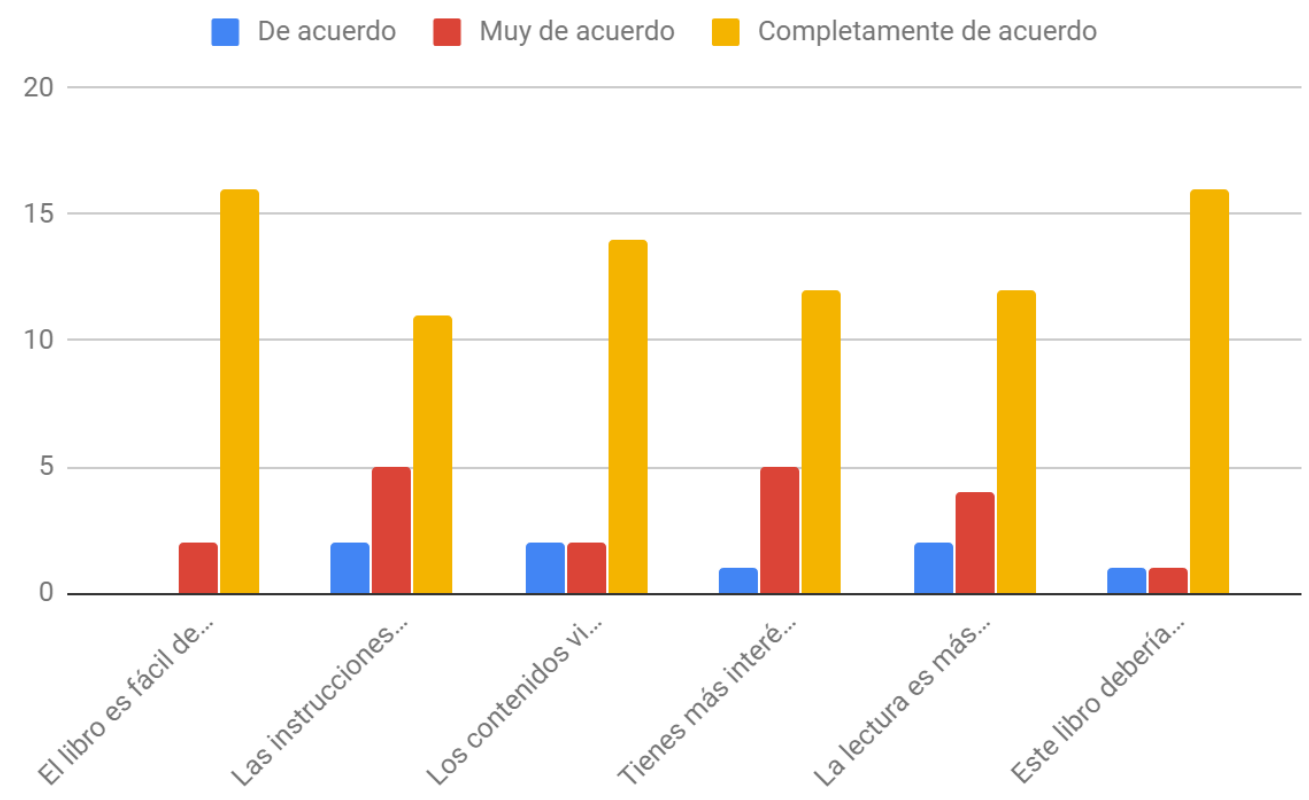

Figura 04. Resultados de la evaluación del libro álbum

Fuente: Elaboración propia del autor, 2020.

Además, en la parte inferior del instrumento se incluyó la posibilidad de agregar una opinión adicional acerca de la obra, para la cual solamente cuatro estudiantes completaron la pregunta, sus respuestas fueron: "El libro nos enseña a valorar más la naturaleza", "Meter un poco más de formas para reciclar", "Me gusta mucho el contenido" y "Es maravilloso pero lo que son las imágenes pueden mejorar".

En síntesis, todos los estudiantes están parcial o completamente de acuerdo con las afirmaciones indicadas en los instrumentos de evaluación del libro álbum. Por lo que puede concluirse que puede ser utilizado con estudiantes de educación primaria diversificada. También, puede afirmarse que el libro no presenta dificultad a la hora de utilizarse, aunque requiere de algunos minutos para que las personas lectoras se familiaricen con este y con sus instrucciones. El uso de realidad aumentada ayuda a despertar interés en la lectura y en los temas que se abordan utilizando esta tecnología, ya que permite comprender mejor el contenido que acompaña. Finalmente, los estudiantes recomendaron utilizar el libro álbum en otros centros educativos. 


\section{Conclusiones}

Es posible vincular la lectura con la tecnología, permitiendo un apoyo a la animación lectora. Dicha integración permite que la persona lectora aumente su interés en la obra al encontrarse con la posibilidad de interactuar con ella más allá del texto y la ilustración que contenga. Parte de las consecuencias de las TIC es el cambio de paradigma relacionado con el texto, el cual pasa de una condición lineal a la hipertextualidad. La tecnología puede aprovechar esta nueva condición del texto para integrar diferentes contenidos (gráficos, textuales y audiovisuales) y así hacer de la lectura una actividad más atractiva, pudiendo capturar la atención de aquellas personas que prefieren la interacción con los juegos, el cine y la televisión antes que con los libros.

Las nuevas aplicaciones de realidad aumentada, por su parte, ofrecen cada vez una mejor integración entre lo virtual y lo real; además, lo permiten con menos necesidad de conocimiento informático. No obstante, dependen de la actualización de los dispositivos, ya que, en el caso de Scope, la aplicación requería de un sistema operativo Android 5.0 o superior, lo que puede significar un limitante si el estudiantado o la biblioteca misma no cuenta con dispositivos con esta actualización.

El material de realidad aumentada no necesariamente debe ser producido por la biblioteca, pueden utilizarse recursos que se encuentren liberados en Internet, tales como vídeos, fotografías, animaciones, modelos en 3D o juegos. Existen distintos sitios web donde se encuentran recursos gratuitos que es posible integrar en aplicaciones de realidad aumentada, pues esta tecnología se basa en la integración de textos, enlaces, vídeos, imágenes o modelos 3D con marcadores impresos, por lo que las posibilidades son muchas.

Por otro lado, se determina que es posible crear desde la biblioteca material didáctico para los docentes mediante el uso de realidad aumentada, pero también es posible generar literatura de entretenimiento o incluso material publicitario para la misma unidad de información. El profesional en Bibliotecología puede encontrar desde su formación los recursos necesarios para auto aprender este y otro tipo de tecnologías; además, la biblioteca puede verse como un centro 
de recursos y un espacio de creación, en tanto cada profesional de la información se dé a la tarea de no solo almacenar la información para sus usuarios sino, también, para generar nuevos productos desde la misma unidad de información.

Es necesario, por lo tanto, que las personas profesionales en bibliotecología se acerquen a esta tecnología y aprendan cómo aplicarla en sus bibliotecas. Este acercamiento permitirá a dichos profesionales diseñar sus propios recursos bibliográficos con realidad aumentada, o bien tener un mayor criterio de elección cuando desee comprar este tipo de materiales para las colecciones de su unidad de información. Es indispensable reflexionar en la necesidad de acompañar este acercamiento con un constante estudio de las tecnologías emergentes ya que, al igual que la realidad aumentada, existen otros recursos que pueden adaptarse para su uso en las bibliotecas.

Además, es importante considerar los resultados obtenidos en la validación del recurso creado. Las nuevas generaciones demandan experiencias más complejas a la hora de consumir contenido, y la animación lectura puede tomar estas condiciones como oportunidades de mejora, de forma tal que el texto lineal que se acostumbra ofrecer como literatura puede acompañarse de recursos tecnológicos que aumenten el interés de las personas más jóvenes a la lectura. Los estudiantes involucrados en esta investigación manifestaron tener mayor interés por la lectura al encontrarse con la posibilidad de interactuar con contenido adicional mediante la realidad aumentada, por lo que es necesario considerar esta tecnología para la creación de programas de animación lectora.

Finalmente, puede considerarse que el uso de la realidad aumentada permite capturar la atención de los más jóvenes por la lectura, y los temas que se elijan para socializar con ellos mediante esta tecnología pueden ser abordados con resultados prometedores en relación con el nivel de interés que ellos muestren. La comunidad estudiantil encontró divertida la lectura tras la integración de esta con la realidad aumentada, también manifestaron tener mejor comprensión de lo que leen al contar con material adicional expuesto con dicha tecnología e indiquen que sería oportuno repetir el ejercicio en otras instituciones. Las TIC están ofreciendo un sin número de posibilidades para innovar los servicios bibliotecarios y prometen resultados favorables en la creación de hábitos lectores en las poblaciones más jóvenes. 
Bibliotecas. Vol. 39, № 1, enero - junio, 2021. EISSN: 1659-3286

URL: http://www.revistas.una.ac.cr/index.php/bibliotecas/index

\section{Referencias}

Arroyo, N. (2016). Experiencias de realidad aumentada en bibliotecas: estado de la cuestión. BiD: textos universitaris de biblioteconomia i documentació, $36 . \quad \mathrm{DOI}:$ http://dx.doi.org/10.1344/BiD2016.36.4

Aumentaty (2019). Aumentaty Community. Estás en la comunidad educativa Aumentaty. [Sitio Web Oficial]. Recuperado de: http://www.aumentaty.com/community/es/

Blázquez, A. (2017). Realidad aumentada en la educación. Recuperado de: http://oa.upm.es/45985/1/Realidad Aumentada Educacion.pdf

Cabero, J., Vázquez, E. y López, E. (2018). Uso de la Realidad Aumentada como Recurso Didáctico en la Enseñanza Universitaria. Formación Universitaria 11(1). 25-34. Recuperado de https://scielo.conicyt.cl/pdf/formuniv/v11n1/0718-5006-formuniv-11-0100025.pdf

Castillo, J. (2011). Proceso lector como instrumento de aprendizaje. Trabajo final de graduación para optar por el título de Maestro en Docencia Universitaria. Universidad de San Carlos de Guatemala. Recuperado de: http://www.repositorio.usac.edu.gt/1216/1/07 2115.pdf

Chaves, L. (2015). Estrategias para el fomento a la lectura: ideas y recomendaciones para la ejecución de talleres de animación lectora. e-Ciencias de la Información (5)2, 1-15. Recuperado de: https://revistas.ucr.ac.cr/index.php/eciencias/article/view/19605

Chaves, L. (2019). La biblioteca: un escenario diverso para la promoción de la lectura. eCiencias de la Información, 9(1). DOI https://doi.org/10.15517/eci.v1i1.35436

Flores, J., Domínguez, C. y Rodríguez, J. (2010). La realidad aumentada como herramienta para mejorar los procesos educativos en la USMP. Boletín electrónico de la Unidad de Virtualización Académica. $10 . \quad$ Recuperado de: http://oei.org.ar/ibertic/evaluacion/sites/default/files/biblioteca/14 realidad aumentada. pdf

Jiménez, L. (2012) La animación a la lectura en las bibliotecas... La construcción de un camino hacia la lectura. Boletín de la Asociación Andaluza de Bibliotecarios. 113. 59-78

Lluch, G., Sánchez, S. (2017). La promoción de la lectura: un análisis crítico de los artículos de investigación. Revista Española de Documentación Científica 40(4). 1-14. Recuperado de https://doi.org/10.3989/redc.2017.4.1450 
Pernas, E. (2009). Animación a la lectura y promoción lectora. En: López Gómez, P. y Santos Paz, J. (Eds). Guía para bibliotecas escolares (pp. 261-290). Universidad de Coruña. Recuperado de: https://core.ac.uk/download/pdf/61911757.pdf

Prendes, C. (2015). Realidad aumentada y educación: análisis de experiencias prácticas. Revista de Medios y Educación, 46. 187-203. Recuperado de: http://www.redalyc.org/articulo.oa?id=36832959008

Ramírez, E. (2009). ¿Qué es leer? ¿Qué es la lectura? Investigación bibliotecológica (23)47, 161-188. Recuperado de: http://www.scielo.org.mx/pdf/ib/v23n47/v23n47a7.pdf Unidad de Currículum y Evaluación. (2007). Ver para leer. Acercándonos al libro álbum. Santiago de Chile: Ministerio de Educación. Recuperado de http://www.bibliotecascra.cl/sites/default/files/publicaciones/verparaleer.pdf

\section{Notas de la persona autora}

Jairo Guadamuz-Villalobos: Académico de la Escuela de Bibliotecología y Ciencias de la Información, Universidad de Costa Rica. Correo electrónico: jairo.guadamuz@ucr.ac.cr ORCID ID: https://orcid.org/0000-0002-0284-3656

* Este artículo es una obra derivada del Trabajo Final de Investigación Aplicada "Creación de un libro álbum con realidad aumentada de la obra La guardiana de la naturaleza y sus amigos salvan el río como apoyo al proyecto Verde que te leo verde de la Fundación Leer / IBBY Costa Rica" 
Bibliotecas. Vol. 39, N 1, enero - junio, 2021. EISSN: 1659-3286

URL: http://www.revistas.una.ac.cr/index.php/bibliotecas/index

VIII. Anexos

\section{Anexo I \\ Formulario de Opinión del Libro Album para estudiantes}

El siguiente formulario busca conocer tu opinión sobre el libro La guardiana de la naturaleza y sus amigos salvan el río utilizado en los talleres de la guía de trabajo Verde que te leo verde. Será de mucha ayuda si contestas las siguientes preguntas. Tus respuestas serán utilizadas con discreción.

Edad:

Sexo:

Después de leer el libro "La guardiana de la naturaleza y sus amigos salvan al río" completa el siguiente cuadro de preguntas, indicando si estás de acuerdo con cada una de las ideas. Para ello debes utilizar la siguiente valoración: 1. Nada de acuerdo (@) 2. Parcialmente en desacuerdo. 3. De acuerdo (-)). 4. Muy de acuerdo. 5. Completamente de acuerdo (৩).

\begin{tabular}{|l|c|c|c|c|c|}
\hline Ideas a calificar & \multicolumn{2}{|c|}{} & - & (2) \\
\hline Ideas & 1 & 2 & 3 & 4 & 5 \\
\hline El libro es fácil de utilizar & & & & & \\
\hline Las instrucciones para instalar Scope son útiles & & & & & \\
\hline $\begin{array}{l}\text { Los contenidos vistos con la tableta ayudaron a } \\
\text { comprender la historia }\end{array}$ & & & & & \\
\hline $\begin{array}{l}\text { Tienes más interés en el medio ambiente y en el } \\
\text { cuento gracias a los contenidos vistos en la } \\
\text { tableta }\end{array}$ & & & & & \\
\hline $\begin{array}{l}\text { La lectura es más divertida al encontrar } \\
\text { contenido adicional usando la tableta }\end{array}$ & & & & & \\
\hline Este libro debería ser utilizado en otras escuelas & & & & & \\
\hline
\end{tabular}

Si lo deseas puedes agregar una opinión adicional acerca del libro 